\title{
FAMILIAL PROGRESSIVE DIFFUSE CEREBRAL SCLEROSIS OF INFANTS
}

BY

\author{
DOROTHY S. RUSSELL, M.D.,* \\ AND \\ KENNETH H. TALIERMAN, M.D., F.R.C.P.
}

The published accounts of progressive familial sclerosis of the brain in infants differ sulliciently in their histopathological details to warrant the description of additional cases of this rare condition, especially when such cases supply connecting links between those already recorded. By such a linking up it will doubtless become possible to recognize and relate phases in a single morbid process and perhaps to simplify the formidable nomenclature that has resulted from the claims of various authors to distinctive types.

In the following examples two infants, a brother and sister, suffered from a cerebral disease which was apparently familial and progressive in nature. Unfortunately the brain of the second child only was available for pathological examination. This example shows a combination of features that renders it different from, although evidently closely related to, certain others already recorded in the literature. After the death of this second child in 1932 a third was born in May, 1933. It has remained in good health up to the time of writing and now, at the age of three-and-a-half years, is normal in every respect. A fourth child, a normal female infant was born in October, 1936 and at the age of four months she was reported to be progressing normally.

\section{Case records}

Case 1. D. D. Male infant, aged 5 weeks.

FAmily history. The parents are Jewish and first cousins. There was no history of disease in the family. This was the first child, and there had been no miscarriages.

History of patient. The infant was a full-term child, weighing $7 \frac{1}{2} \mathrm{lb}$. at birth, after a normal labour. He was fed at the breast, with supplementary feeds of a condensed milk mixture. He was quite well until the age of two weeks when he had a fit of crying, lasting four hours. On the

* Working for the Medical Research Council at the Bernhard Baron Institute of Pathology, the London Hospital. 
following day he appeared well, but was unable to suck properly. Fifteen days before admission to hospital he still was unable to suck, and was fed by spoon. At this time he had a convulsion, and some head retraction was noted; the mouth was kept open. Owing to the fact that he was taking food and fluid badly, and was dehydrated, a diagnosis of 'dehydration fever' was made. Subsequently further convulsions occurred, and three days before admission to hospital he was noted to be sleepy; he was hardly able to swallow, and fluids ran out of his mouth.

On December 19, 1929, he was admitted in a comatose condition to the Children's Department of the London Hospital, under the care of Dr. A. G. Maitland-Jones, by whose courtesy the case is reported. The temperature was then $97^{\circ} \mathrm{F}$. The lungs, heart, and abdomen were normal. The legs were spastic; the knee jerks were equal and exaggerated; the optic discs were normal. On 20.12.29 some twitching of the face was noted. There was great difficulty in swallowing. The cerebro-spinal fluid was under pressure, and was blood-stained, but this was probably due to trauma from the needle. There was no excess of white cells, the protein content was $0 \cdot 8$ per cent. and the Wassermann reaction was negative. On 22.12.29 death occurred, just before which the temperature rose to $100 \cdot 8^{\circ} \mathrm{F}$. No postmortem examination was obtained. A diagnosis of cerebral haemorrhage was made. In the light of subsequent events, however, this seems to be incorrect, and it appears justifiable to regard the condition as one of familial progressive diffuse cerebral sclerosis.

Case 2. C. D. Female infant, aged 6 months.

Family history. The one previous child died as a result of cerebral disease, as described above. No other history of illness.

History of patient. The infant was born at full term, weighing $7 \frac{1}{4} \mathrm{lb}$., and the labour was normal. At birth the child was apparently healthy in every way, and she remained so for the first three to four months, except that she was never hungry, and would take about an hour on an average over each feed, sucking spasmodically. She would become less and less inclined to feed as the day progressed, so that by the time the last feed was due, at 10 p.m., she could seldom be induced to take anything. In spite of this she put on weight steadily, about 4 to $5 \mathrm{oz}$. weekly, was a moderately active child, with a normal cry, and slept well. At five weeks of age she refused absolutely to take a breast feed, and was put on a dried milk mixture. There was slight vomiting from time to time, but this was never serious, and later ceased. At three-and-a-half months of age she developed what was described as a ' bad cold in the eyes.' Both eyes were closed by a swelling of the lids which lasted four or five days, and then gradually subsided; there was no accompanying nasal catarrh or cough. At about four months of age she became less active, and appeared to be growing weaker, the arms and legs being slightly stiff. Her healthy cry now changed into a prolonged whimper, and she gradually failed to show any definite recognition of any person or thing. About this time twitching was noticed in the left side of the face, the left arm, and the left leg, but this passed off. At five months she began to cry whenever she was handled. On account of this and her other abnormalities she was seen in consultation by one of us (K. H. T.). There was no history of attacks of cyanosis, and no fever had been noted. The bowels moved normally.

On examination. 29.11.31. The infant weighed $14 \mathrm{lb} .5 \mathrm{oz}$. There were no definite neurological signs : no head retraction, nor apparent cervical rigidity; no bulging of the anterior fontanelle; no signs of deafness. The 
limbs appeared to be moved normally. The knee jerks were equal and normal. The pupils reacted to light, and no abnormality was noted in the fundi, but they were difficult to examine. The eyelids were puffy, and the eyes had a staring appearance. The heart was not enlarged, but there was a systolic murmur, unaccompanied by thrill and localized to the second and third left inter-costal spaces close to the sternum.

It was considered at this time that the child might be suffering from some form of cerebral degeneration, but there was no definite evidence of this, and the acute symptoms appeared to be due to feeding irregularities, which might be held responsible for colic and difficulty in taking the feeds. These irregularities were corrected and the diet adjusted, but the child failed to progress, and after about three weeks developed gastro-enteritis with blood-stained motions, and at the same time definite spasticity of the limbs and general rigidity. On this account she was admitted to Paddington Green Children's Hospital.

ON ADMission. 22.12.31. Clinical examination revealed a wellnourished infant, weighing $12 \mathrm{lb} .8 \mathrm{oz}$. , who remained lying on her side, with eyes usually closed (there being now no oedema of the lids), head slightly retracted, arms flexed with fingers tightly clenched, and legs and feet stiffly extended. She showed no signs of visual recognition, nor of auditory sensation. She did, however, show by whining a resentment at being moved. The anterior fontanelle was open, and neither depressed nor bulging. The ear drums were normal. The left optic disc was rather pale; there were no changes in the vessels, no papilloedema, and no abnormality of the macula. The right fundus appeared normal. There was slight rigidity of the neck muscles, and marked rigidity of the arms and legs, the arms being in semi-flexion with the fists tightly clenched, and the legs in extension. The knee jerks were slightly increased; owing to rigidity there was difficulty in eliciting ankle and triceps jerks. The plantar response was extensor on both sides, and the abdominal reflexes were absent. The heart showed the same signs as on the previous examination. There was no clubbing of the fingers, no cyanosis, and no dilatation of veins.

Lumbar puncture produced a clear fluid under slightly increased pressure, showing no abnormality: the Wassermann reaction was negative, and the urea content $18 \mathrm{mgm}$. per 100 c.c.

A specimen of urine obtained by catheter was normal. There was a slight vaginal discharge, and in a non-catheter specimen some pus cells were noted.

Progress. 29.12.31. The child was still sucking extremely badly, and would hardly take feeds at all, the milk having to be poured from the bottle into her mouth. There was no vomiting, and the motions were normal. She was more lethargic than ever, and remained motionless, with eyes closed, head slightly retracted, arms semi-flexed, and legs extended. She was, however, gaining weight satisfactorily.

The fundi were examined by Mr. Frank Law, who reported that vision appeared defective, but it was difficult to form an accurate opinion regarding this, in view of the child's condition. Both discs appeared to be within the limits of normality, and there was no papilloedema. There were no mascular lesions to be observed, and the vessels were normal. The child did not follow a light with her eyes, but there was a slight sluggish contraction of the pupils to light. There was no reaction to any loud noise.

31.12.31. There was now great difficulty in swallowing, and almost continuous dribbling from the mouth; the child had to be fed by tube. 
2.1.32.* The attitude now suggested complete decerebrate rigidity (fig. 1). Both pupils showed a very sluggish and slow reaction to light, and a consensual reaction-the right rather stronger than the left. There was a doubtful grasp reflex of the hands, but none of the feet. The tone of the arms, in both extension and flexion, was influenced by the position

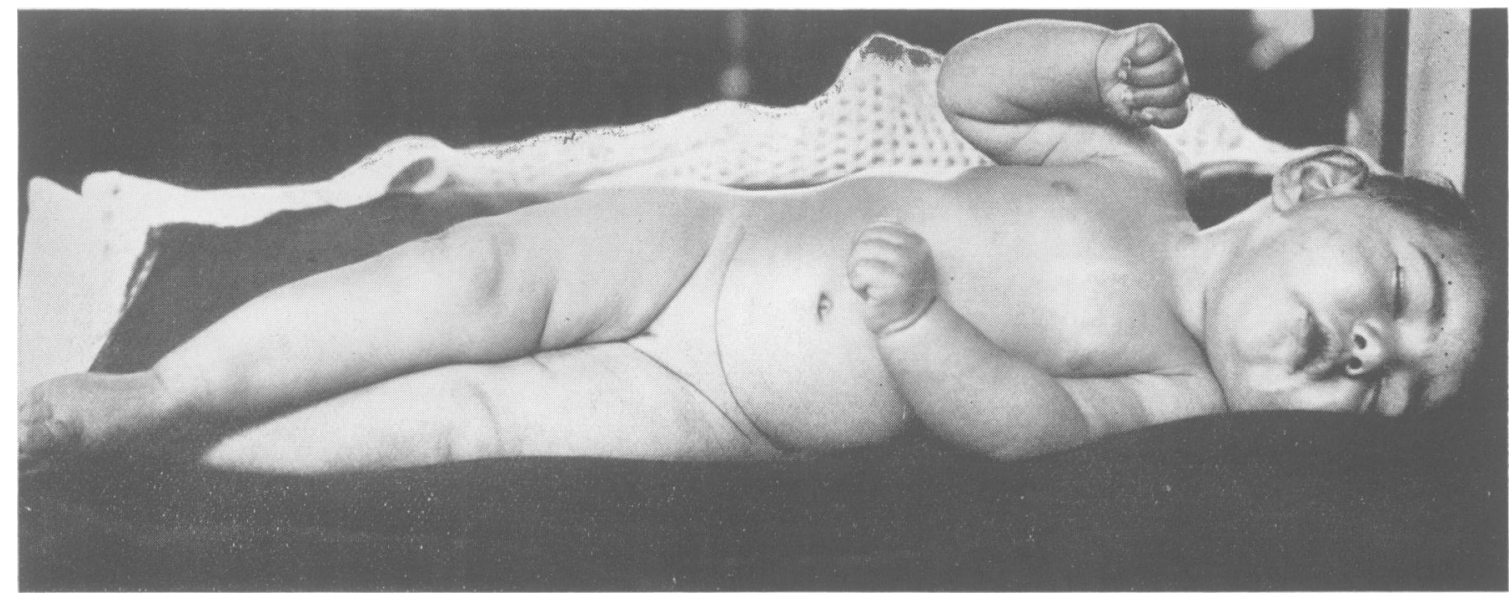

FIG. 1.-C. D., 2 days before death.
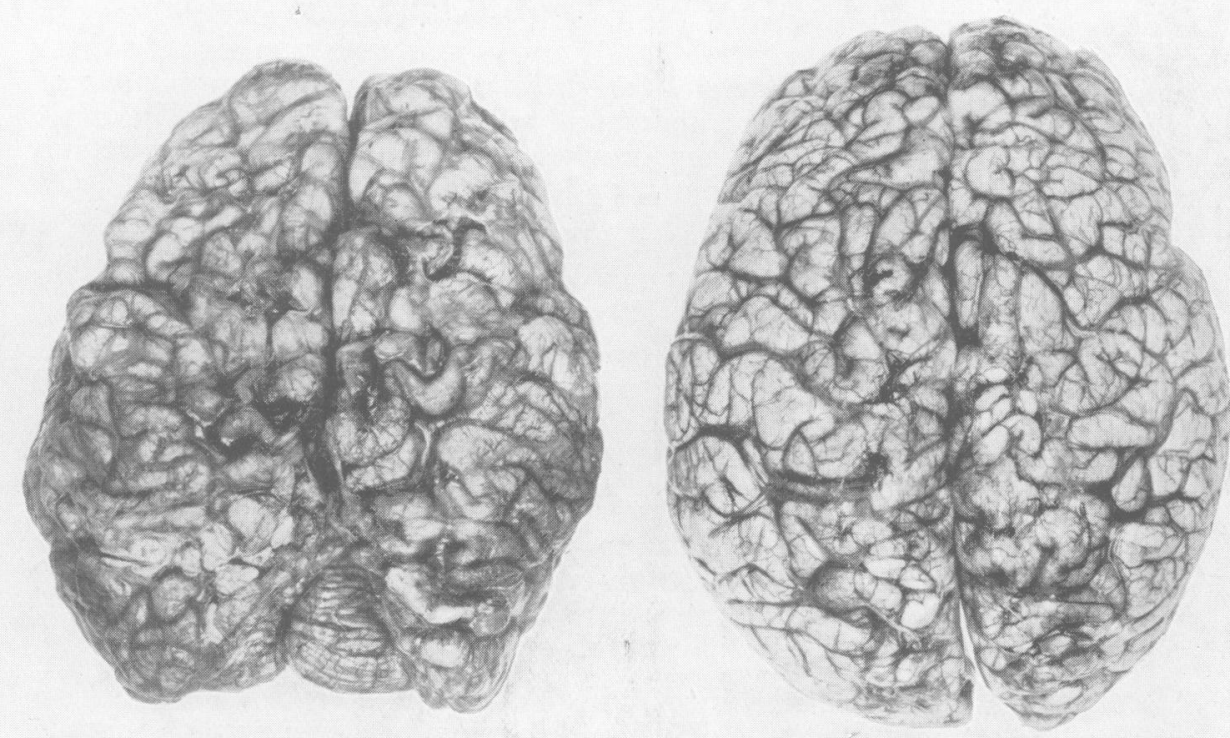

FIG. 2.-Dorsal view of brain after fixation; on right, control of same age.

of the head: when the head was turned to the left or to the right, the extension tone of the left or the right arm respectively was increased. Both extension and flexion reflexes could be elicited in each arm, depending upon the position of the head. Similar tone responses in the legs could be elicited.

\footnotetext{
* Patient seen in consultation with Dr. W. R. Brain.
} 
5.1.32. Weight, $12 \mathrm{lb} .10 \mathrm{oz}$. Mr. F. Law now reported that the left optic disc was pathologically pale, and the right disc appeared to be becoming so.

Diagnosis was made of progressive familial cerebral degeneration, and congenital morbus cordis.

6.1.32 The child was unable to swallow.

7.1.32. Death occurred at 3 a.m. There was no terminal fever, and throughout her stay in hospital the child had been afebrile.

\section{Pathological examination*}

Necropsy. Permission for examination was restricted to the head. The brain when exposed appeared abnormally small and somewhat congested. The cerebral convolutions were narrow and worm-like and were separated by abnormally wide sulci (fig. 2). The subarachnoid spaces contained an excess of cerebrospinal fluid, the leptomeninges being normal except for slight opacity over the circle of Willis. The cerebral atrophy was most conspicuous in the fronto-parietal region and was not appreciable either in the temporal lobes or on the ventral aspect of the hemispheres.

After fixation in formaldehyde the brain weighed 14 oz. (397 gm.) representing approximately a fourteenth part of the total body weight. The brain of a control male infant of the same age weighed $25 \mathrm{oz}$. (709 gm.), a sixth part of the total body weight. Comparison with the control also showed a considerable flattening of the hemispheres and atrophy of the lateral cerebellar lobes. The brain as a whole felt abnormally soft but on section the texture varied greatly in different areas. The white matter was soft throughout the greater part of the hemispheres, and appeared friable and greyish-yellow beneath most parts of the cortex. Demarcation of the cortex and white matter was blurred. The white matter of the convolutions was extraordinarily spongy, containing small irregular spaces measuring up to $3 \mathrm{~mm}$. in diameter. Such convolutions appeared greatly wasted, but the basal parts more so than the tips so that, on the cut surfaces, the convolutions were often club-shaped (fig. 3). A similar spongy change was present in the external capsule and island of Reil. Numerous sharply defined cystic areas (up to $0.4 \times 0.2 \mathrm{~cm}$.) were scattered throughout the basal ganglia with the exception of the caudate nuclei (fig. 5). They were mostly grouped about the internal capsule, occupying both the lateral border of the optic thalamus and the globus pallidus. In the parieto-occipital region, in the putamen, and in scattered ill-defined areas beneath the cortex of all lobes the brain was ivory-white and its texture was very tough and rubbery. This alteration caused considerable obscuration of the pattern in the posterior parts of the basal ganglia.

Foci of greyish-white softening were present in the tegmental part of the mid-brain; the rest of the brain stem appeared normal. The changes in the cerebellum resembled those in the cerebrum. The folia were narrow and atrophied (fig. 7). An opaque creamy-yellow line separated the cortex from the white matter and the latter was for the most part spongy with a slight greyish discoloration. The central parts of the lateral lobes were rather firm and rubbery.

A relative degree of internal hydrocephalus was present, affecting chiefly the posterior horns of the lateral ventricles. The ependyma everywhere was smooth and glistening and the choroid plexuses appeared normal.

Microscopic examination. The leptomeninges appear normal except for the presence of occasional groups of lymphocytes and plasma cells near the blood vessels upon the convexities. There is no infiltration of the basal leptomeninges.

* London Hospital records-P.M. 586, 1930, Appendix. 
FIG. 4.-Control for fig. 3. Corresponding part of frontal cortex showing myelination. Loyez haematoxylin. $\times 3 \cdot 3$. 


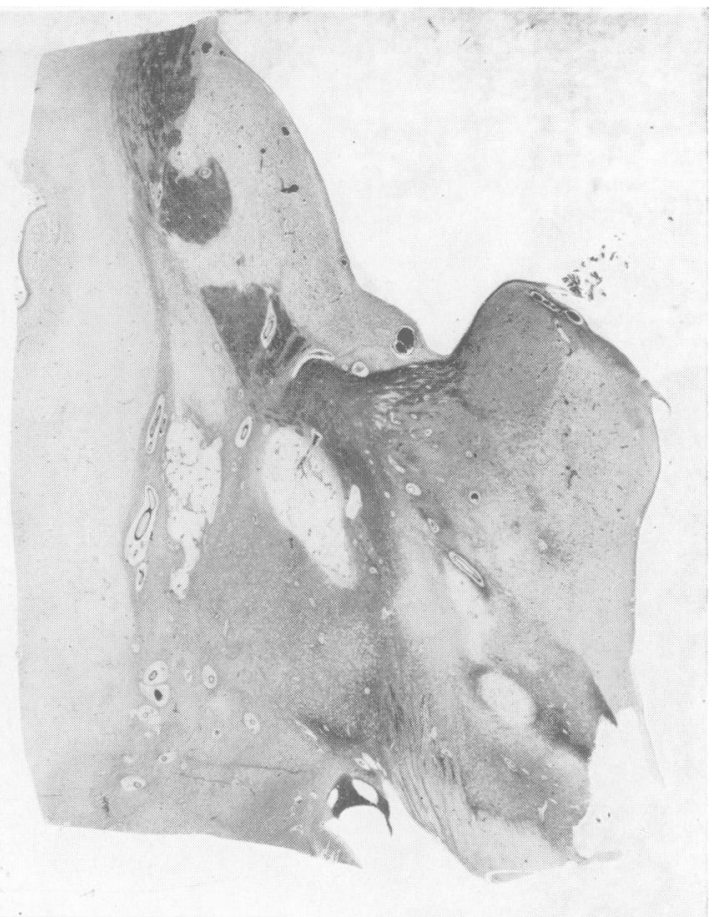

Frg. 5.-Coronal section of basal ganglia showing atrophy, cystic areas and loss of myelin. Loyez haematoxylin. $\times 3$.

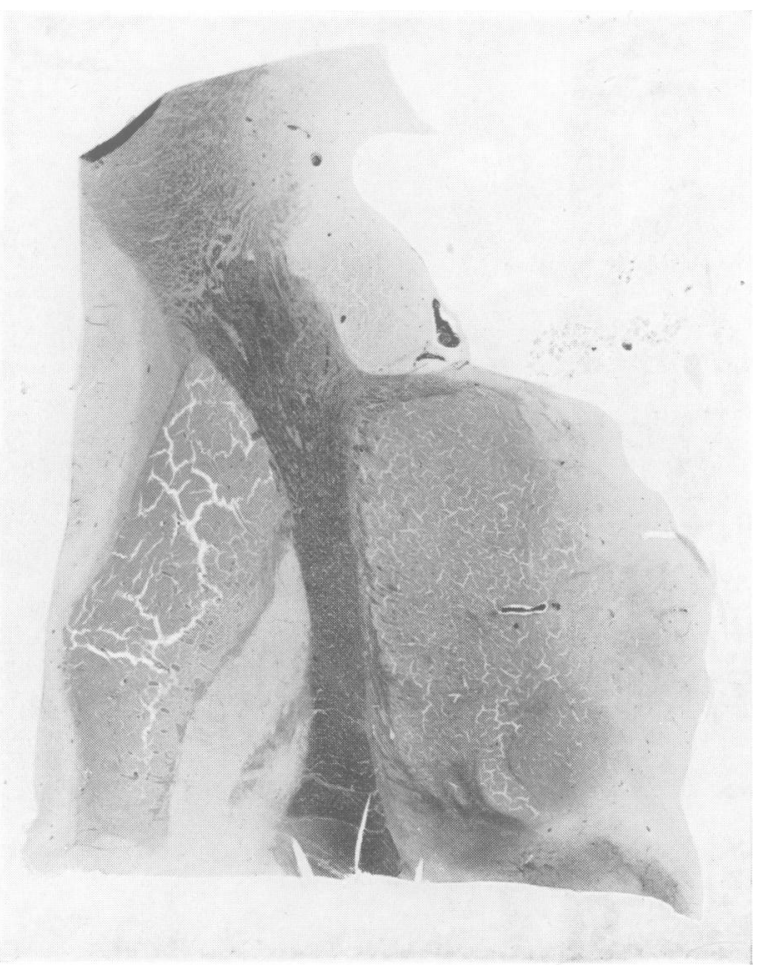

Fig. 6.-Control for fig. 5, showing normal pattern and myelination in infant of same age. Loyez haematoxylin. $\times \mathbf{3}$. 
FIG. 8.-Control of same age showing normal contours and myelination. Loyez haematoxylin. $\times 4$.

G. 7.-Cerebellum showing atrophy of folia and great loss of myelin, except at summits of folia. Loyez haematoxylin. $\times 4$.

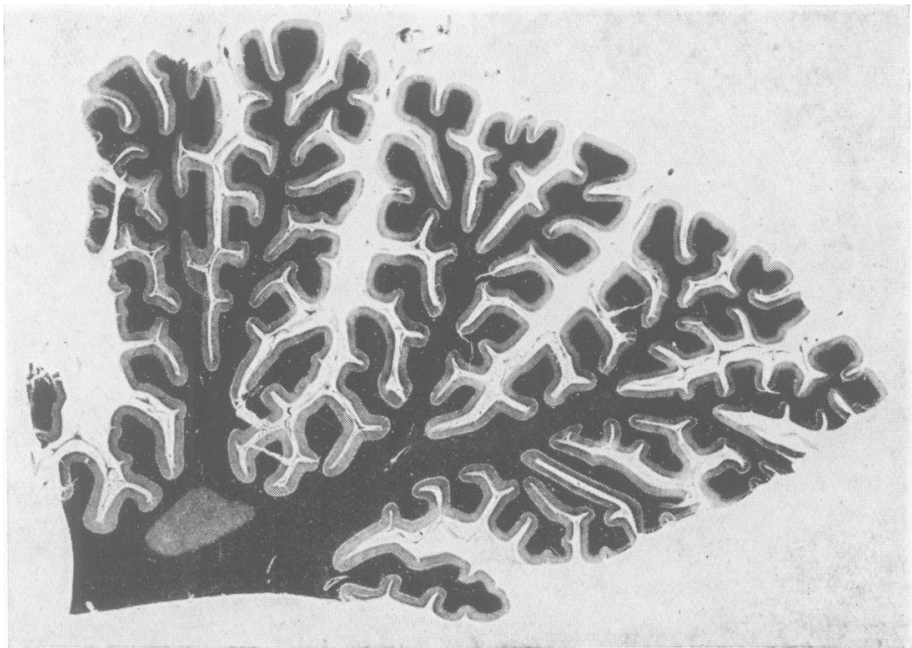


In the cerebrum degenerative changes are in general pronounced. In the hippocampus alone the normal structure is preserved and the myelinated fibres are here intact. In the convolutions of the adjacent temporal lobe there is a gradual transition to the changes that prevail in all other parts of the cerebral convexities that were examined. In these there is great destruction of the cortex except at the summits of the convolutions (fig. 3). Here the pyramidal cells are recognizable and are of nomal size and shape but their nuclei appear vesicular and the Nissl bodies are scanty and are confined to the periphery of the cell. No lipoid inclusions are present in Herxheimer and Marchi preparations. In the depths of the sulci there is often a complete absence of bodies of neurones and decreasing stages of degeneration can be traced as the summits are approached. Myelin sheaths cannot be recognized in the cortex. In Bielschowsky preparations both tangential and radial axis cylinders are present at the summits of the convolutions and they appear well preserved; in the cortex in the depths of the sulci a few tangential axis cylinders only are recognizable. Associated with this destruction of neurones and proportional to it is a conspicuous infiltration of the cortex with amoeboid forms of microglia containing lipoid material giving a positive reaction with the Herxheimer and Marchi methods. These cells sometimes lie in an irregular, ill-defined zone beneath the pia and form discrete foci in deeper parts of the cortex. Numerous astrocytes are also present in the depths of the sulci (fig. 11). They are often fibrillated and have relatively large cell bodies with clear, glassy cytoplasm. In places the cortex is entirely replaced by diffuse patches of dense fibrillary gliosis. There is no infiltration with cells of the types that characterize known infections. The adjacent white matter is often honeycombed with small irregular spaces, especially in the convolutions. Such areas show extremely few axis cylinders in Bielschowsky preparations and their course is disturbed by the presence of the spaces. Loyez and Weigert Pal preparations show conspicuous degrees of demyelination when compared with a normal control of the same age (fig. 3 and 4). The naked-eye appearance of Weigert-Pal preparations of a coronal section through the whole hemisphere in the parieto-occipital region corresponds approximately, in the degree of myelination, to Flechsig's demonstration ${ }^{3}$ in a child of four months. The optic radiations are well preserved. With high magnification extensive destruction of the myelin is demonstrated by ballooning of the sheaths and by wide dissemination of globular fragments of myelin of various sizes. The deficiency of myelin is in general diffuse throughout the centrum ovale and does not appear excessive in perivascular areas. Associated with this loss of myelin and proportional to it is an overgrowth of fibrillary astrocytes. These astrocytes, like those present in the cortex, have a somewhat swollen cytoplasm and in Herxheimer and Marchi preparations frequently contain small granules of fatty substances. The Marchi preparations do not show droplets of fat outside the cells. No infiltration with cells of the types that characterize known infections is present, and the blood vessels are unaltered except for occasional cuffs of lipoid-containing cells in the adventitial sheaths. The oligodendroglial cells are not noticeably reduced in number. Those present in areas of degeneration and gliosis show advanced degrees of ' acute swelling,' often reaching the stage where the nucleus is very pyknotic and the cytoplasm is disintegrating.

The changes in the cerebellum resemble those noted in the cerebral hemispheres. The cortex shows great destruction with replacement of its normal elements by numerous astrocytes and amoeboid microglial cells containing lipoid, except at the summits of the folia where the superficial embryonic granular layer, inner granular and Purkinje cells are demonstrable (fig. 7). The Purkinje cells show stages of degeneration, which 
become more intense as the depths of the sulci are approached. Here these cells are usually absent and the granular cells are greatly reduced in numbers. The white matter shows extreme demyelination and porosity. In Bielschowsky preparations the axis cylinders are greatly reduced in numbers; those present are well preserved but are displaced by the numerous pores. These degenerative changes are accompanied by great gliosis, especially near the centres of the lateral lobes. There are only a few fatgranule cells in these central parts but they become ever more abundant as the cortex is approached. The astrocytes on the other hand often contain granules of fatty material. There is a considerable reduction in the numbers of oligodendroglial cells throughout the white matter.

In the basal ganglia the cystic areas observed with the naked eye are crossed in places by vascularized trabeculae of neuroglia coated with

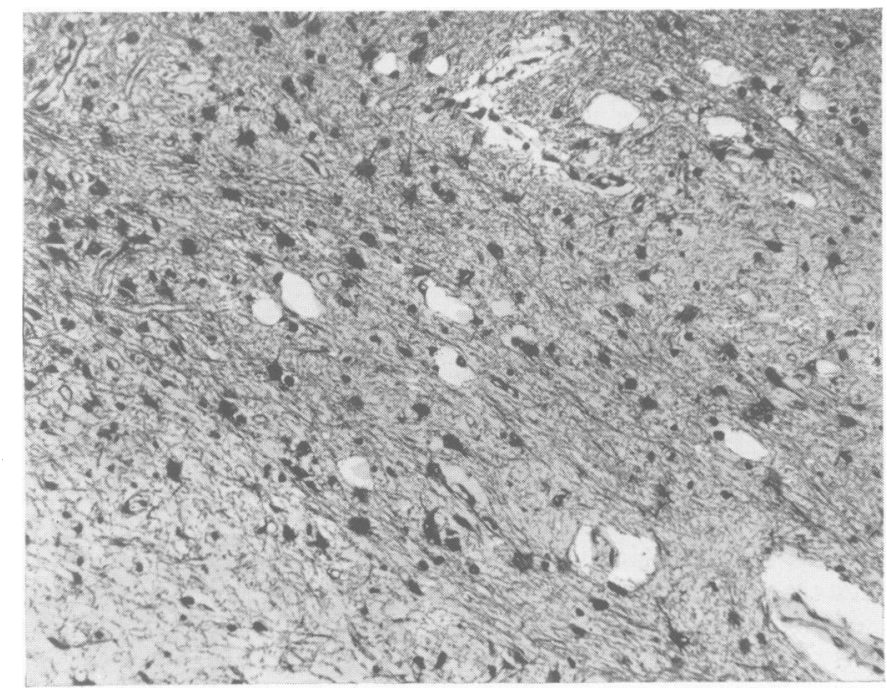

FIG. 9.-Lenticular nucleus showing dense fibrillary gliosis. Mallory's phosphotungstic acid haematoxylin. $\times 159$.

amoeboid microglial cells containing lipoid droplets. A few of these cells lie in the cavities, which are otherwise empty. In one of the trabeculae a vessel shows endarteritis fibrosa and perivascular infiltration with lymphocytes and a few plasma cells. No endarteritis was found elsewhere and perivascular infiltration of the same character was found only in two vessels attached to the right ventricular choroid plexus and in one perforating vessel in the pons. In Herxheimer preparations there are cuffs of fat granule cells in the perivascular sheaths of many vessels and a few amoeboid microglial forms containing fat are diffusely distributed beneath the ependyma covering the optic thalami. The ependyma is intact. There is gliosis with loss of bodies of neurones in the globus pallidus becoming more intense in the putamen, which is occupied by a gliosis which is so dense and cellular that it resembles an astrocytoma (fig. 9, 10). The optic thalamus and caudate nucleus are less affected, the degeneration of bodies of neurones and gliosis 


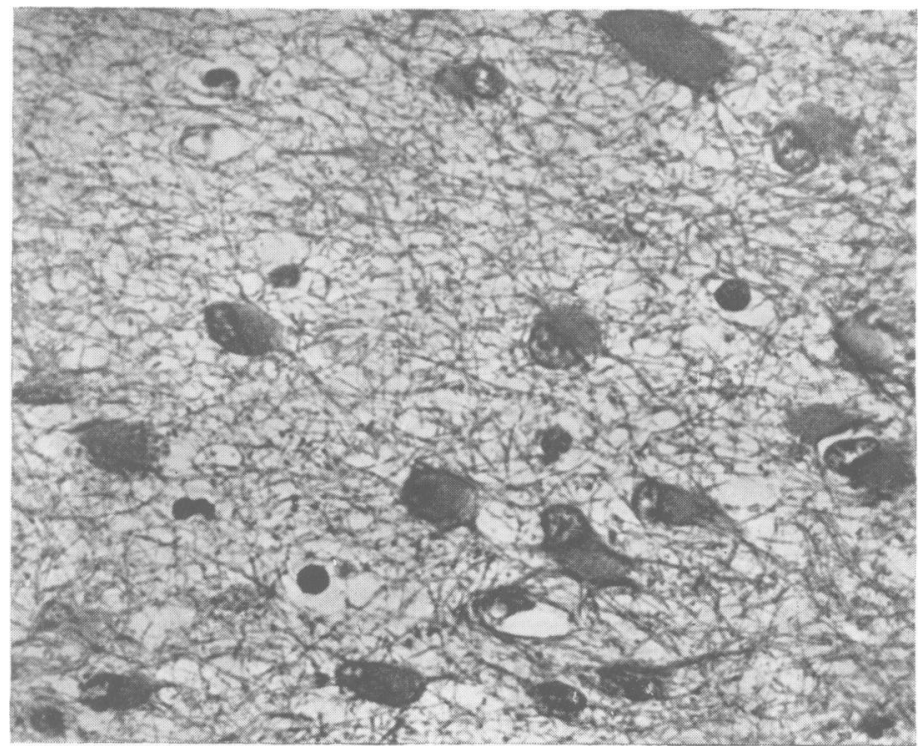

Fig. 10.-Same as fig. 9 to show estrocytes and fibrils. $\times 600$.

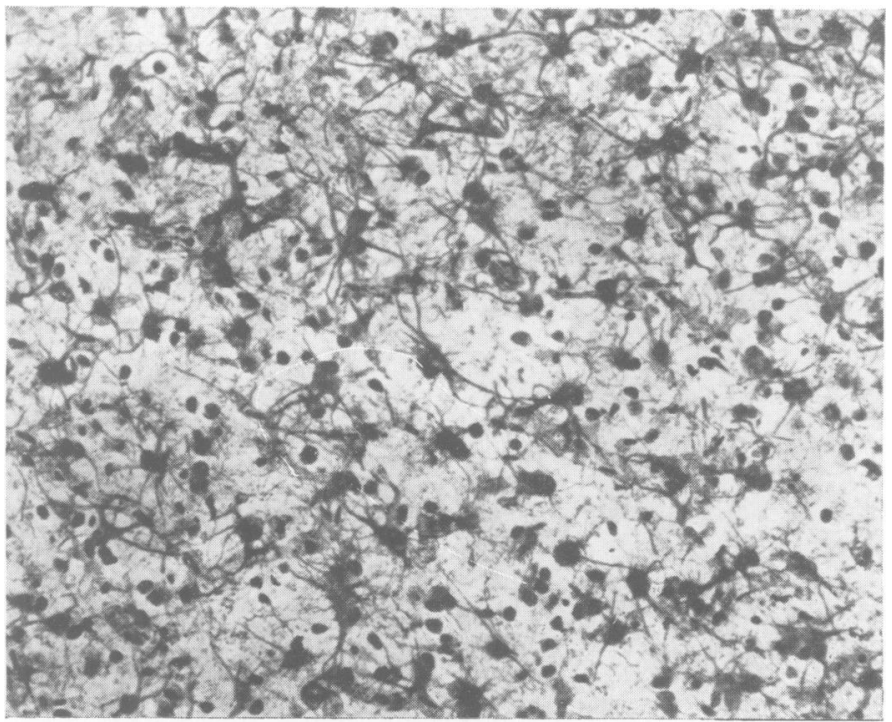

FIG. 11.-Occipital cortex in depths of a sulcus showing excess of fibrillary astrocytes. Hortega's silver carbonate (Penfield's modification). $\times 190$ 
being less conspicuous. The lateral parts of the thalamus, adjacent to the internal capsule, are more affected than the medial and show, in Hortega preparations, an excess of microglial cells. There is great fragmentation of myelin in the internal capsule and here, as elsewhere, the process is diffuse. Bielschowsky preparations show great loss of axis cylinders in areas of degeneration. In the internal capsule they are surprisingly well preserved and appear fairly numerous. The hypothalamus appears normal and the optic tracts are well myelinated.

In the mid-brain degeneration is limited to a few symmetrical areas in the tegmental region. The largest of these occupies the medial fillet, arching round and encroaching on the dorso-lateral aspect of the red nucleus. Other smaller areas lie on either side of the aqueduct. Gliosis and fragmentation of myelin are visible in these areas and, in frozen sections, fat-containing microglial cells are present. The oculo-motor nuclei appear porous and contain a few collections of fat-granule cells. The bodies of neurones however are well preserved. Gliosis is most marked in the red nuclei and is also conspicuous throughout the tegmental region, continuing with decreasing intensity caudalwards to fade away in the upper medulla. The oligodendroglial cells do not appear to be reduced in numbers; they have undergone only slight degrees of acute swelling except in the areas of degeneration mentioned. The cranial nerve nuclei appear well preserved.

\section{Summary of pathological examination}

The pathological process appears to be a widespread degeneration affecting principally the cerebral and cerebellar white matter, but also involving the cortex in both situations. Degeneration is demonstrated macroscopically by atrophy of the brain attended by softening and porosity of its substance and microscopically by evidence of demyelination accompanied by a marked microglial reaction and an uneven gliosis. The oldest lesions appear to occupy the white matter of the parieto-occipital regions, putamen and the central parts of the lateral cerebellar lobes; foci of approximately equal age are scattered throughout the remaining parts of the cerebral hemispheres. The cerebral and cerebellar convolutions appear in general to have been more recently affected. A remarkable feature is the constant involvement of the cortex in the depths of the sulci and its relatively good preservation at the summits of the convolutions. Apart from the hippocampal convolutions, the hypothalamus and optic tracts, which appear unaltered, the degeneration is remarkably diffuse and there is no evidence of an initial perivascular distribution. The extreme degeneration of the oligodendroglial cells accords with other evidence of degeneration. It is well known that these cells are particularly vulnerable; their sensitivity is manifested by a series of changes known as ' acute swelling' (Penfield and Cone $^{12}$ ), the early stages of which can be detected within a few hours of death. In these circumstances it is not believed that the cerebral changes as a whole are attributable to an initial attack upon the oligodendroglia, as has been suggested by Hortega in connection with Schilder's disease and by Greenfield $^{5}$ in his description of two cases of progressive cerebral sclerosis in infants.

Evidence of inflammation of the kind that characterizes known infections is limited to scanty focal meningeal and perivascular infiltration with lymphocytes and plasma cells; in one vessel there is endarteritis fibrosa. There is no evidence of vascular proliferation in any part of the brain 
examined. The cerebellum shows the same widespread destructive changes as the cerebrum. Apart from foci in the tegmental region the brain stem and cranial nerve nuclei are unaffected. The spinal cord was not available for examination.

\section{Discussion}

Estimation of the intensity of the demyelination is rendered exceedingly difficult by the age of the child, the onset of the disease having taken place at a time when the brain is normally undergoing rapid myelination. The fact that the disease in this instance began at about the age of four months and that Weigert-Pal preparations of some parts of the brain corresponded approximately with Flechsig's demonstration in an infant of four months might suggest that the appearances seen are due to an inhibition, or alternatively an aplasia, of normal myelination rather than to an active destruction of formed myelin. This view is unacceptable because it offers no explanation of the porous areas and small cysts in the white matter and basal ganglia, nor is it likely that a purely passive inhibition would be attended by the conspicous microglial reaction seen in this case. Moreover in areas, such as the Rolandic, where myelination is normally completed at an earlier age there is evidence of a conspicuous loss. An active degeneration is also indicated by the widespread involvement of the cortex resulting in the loss of bodies of neurones and a replacement gliosis (fig. 11). It is, however, reasonable to assume that, in the presence of a degenerative process of this character, the normal process of myelination would be in abeyance.

The remarkable absence both of infiltration with cells of the types that characterize known infections and of vascular proliferation further identifies the pathological process as a degeneration. There is no evidence from either a clinical or pathological standpoint of the nature of the damaging agent. The swollen bodies of the astrocytes in areas of gliosis (fig. 10) resembling the so-called 'gemästete' glia cells and the extreme degrees of acute swelling of the oligodendroglia are suggestive of the action of a toxin.

Diagnosis. Although the familial incidence, Jewish parentage and clinical picture are suggestive of family amaurotic idiocy this diagnosis is ruled out by the absence of the characteristic macular changes and by the histological appearances of the brain. In particular there was no storage of lipoids in the neurones.

Familial examples of diffuse cerebral sclerosis have been described in young children, notably the familial infantile form of ' diffuse brain 
sclerosis' of $\mathrm{Krabbe}^{7}$, ' aplasia axialis extracorticalis congenita' or Pelizaeus-Merzbacher's disease (Pelizaeus ${ }^{11}$; Merzbacher $^{8}$ ), and the ' gressive subcortical encephalopathy' of Globus and Strauss ${ }^{4}$. Case 2 resembles Krabbe's cases clinically not only in the onset in early childhood and the rapid progression of the disease, but in respect of the presumptive familial tendency. Pathologically there is in both a conspicuous gliosis and demyelination of both cerebrum and cerebellum. The perivascular sheaths are infiltrated with fat-granule cells and there is remarkably little infiltration with cells of the types that characterize known infections. The present case, however, differs in the marked involvement of the cortex in both cerebrum and cerebellum, the occurrence of porous areas in the white matter accompanied by great irregularity in the glial proliferation, and the presence of numerous fat-granule cells in the brain parenchyma. These inconsistencies however are probably not indicative of any fundamental difference in the nature of the process, but may be interpreted as evidence of a more rapid destruction of the brain tissue in the present case with death at a time when scavenging and gliosis were incomplete. This interpretation finds some support in the description by Globus and Strauss ${ }^{4}$ of four cases of Krabbe's type. In their third case in a female infant of six-and-a-half months, clinical deterioration was rapid, death occurring four days after the apparent onset of the illness. The brain in this case showed a diffuse but less uniform destruction of myelin than in their more chronic cases, associated with a ' status spongiosus' of the subcortical tissue. 'Transitional forms leading to the formation of compound granular corpuscles were also found.'

The present case is distinguished from Pelizaeus-Merzbacher's disease again by the involvement of the cortex but more particularly by the conspicuous gliosis in both cortex and white matter, which has not been demonstrated in this form. While the clinical and histological features of the present case are strongly suggestive of Schilder's disease the involvement of cortex again might be considered to weigh heavily against this diagnosis, as does the apparent familial incidence. Bouman ${ }^{1}$ has, however, pointed out (p. 120-121) that some degree of cortical change has been recorded by numerous observers in Schilder's disease. Of special interest, in comparison with the present case, is the description by Neubürger ${ }^{10}$ of degeneration of the deepest layer of the cortex in the neighbourhood of the arcuate fibres. Bouman also finds (p. 104) that familial instances of diffuse sclerosis are now being reported with greater frequency. This statement has recently been repeated by Meyer and Tennent ${ }^{9}$ in their paper on a fresh instance of familial Schilder's disease. The resemblance between these familial cases in infants and Schilder's disease is indeed emphasized by Globus and Strauss who regard both as a degenerative condition of toxic origin and suggest 
that they should be grouped under the general name of 'progressive degenerative subcortical encephalopathy.' The inter-relationships of these groups and their possible kinship with disseminated sclerosis has been discussed by Bouman, who gives a comprehensive review of the literature.

Etiology. It is generally agreed that the etiology of all these forms of diffuse sclerosis is quite obscure. The possibility that viruses are responsible for the so-called demyelinating diseases of the central nervous system has been entertained for some years by competent authorities. In this connection the recent investigation by Innes ${ }^{6}$ into a disease of lambs, ' swayback,' which resembles Schilder's disease in man, is of the greatest interest and importance. He states that ' all attempts to incriminate either bacteria or a virus have failed, and it appears improbable that these play any part in the etiology.' The causal agent, whatever it is, exerts its action while the lambs are in utero and does not appear to affect the health of the pregnant ewes. Innes discusses the possibility that lead may play some part and points out that punctate basophilia was found in many of the lambs with 'swayback.' In this connection it is of interest that Cone, Russel and Harwond ${ }^{2}$ have independently found evidence suggesting that lead may be responsible for disseminated sclerosis. On the other hand, Rivers and Schwentker ${ }^{13}$ have succeeded in prcducing an experimental encephalomyelitis accompanied by myelin destruction in a series of monkeys by injections of heterologous brain material. They were unable to demonstrate any infective agent to which the lesions might be attributed. Another theory attributes cerebral sclerosis in infants to an aplasia of myelin. This may he more readily applied to cases of the Pelizaeus-Merzbacher type in which the cortex is unaffected and there is no histological evidence of active myelin destruction. But on this basis it might be expected that symptoms would $b_{2}$ ? apparent from the time of birth, which in general is not observed. In the present case the theory is unacceptable for reasons that have already been given.

In view of our ignorance of the etiology it is considered that nothing is to be gained by elaborating the classification of these cases. The present example is regarded as essentially of the same type as those described by Krabbe, by Globus and Strauss and by Greenfield. It is suggested that the term ' familial progressive diffuse cerebral sclerosis' is sufficiently descriptive of the condition.

\section{REFERENCES}

1. Bouman, L., Diffuse sclerosis (encephalitis periaxialis diffusa), Bristol, 1934.

2. Cone, W., Russel, C., and Harwood, R. U., Arch. Neurol. \& Psychiat., Chicago, 1934, XXXI, 236. 
3. Fleschsig, P., Anatomie des menschlichen Gehirns and Rückenmark auf myelogenetischer Grundlage, Leipzig, 1920, I.

4. Globus, J. H., \& Strauss, I., Arch. Neurol. \& Psychiat., Chicago, 1928, XX, 1190.

5. Greenfield, J. G., Proc. Roy. Soc. Med., London, 1933, XXVI, 690.

6. Innes, J. R. M., ibid., 1936, XXIX, 24.

7. Krabbe, K., Brain, London, 1916, XXXIX, 74.

8. Merzbacher, L., Ztschr. f. d. ges. Neurol. u. Psychiat., Berlin, 1910, III, 1.

9. Meyer, A., \& Tennent, T., Brain, London, 1936, LIX, 100.

10. Neubürger, K., Zeitschr. f. d. ges. Neurol. u. Psychiat., Berlin, 1921, LXXIII, 36.

11. Pelizaeus, F., Arch. f. Psychiat., Berlin, 1885, VI, 698.

12. Penfield, Wilder, \& Cone, W., Arch. Neurol. \& Psychiat., Chicago, 1926, XVI, 131.

13. Rivers, T. M., \& Schwentker, F. F., J. Exper. Med., New York, 1935, LXI, 689. 